\title{
Endozoochory largely outweighs epizoochory in migrating passerines
}

\author{
José M. Costa, Jaime A. Ramos, Luís P. da Silva, Sérgio Timoteo, Pedro M. Araújo, \\ Marcial S. Felgueiras, António Rosa, Cláudia Matos, Paulo Encarnação, \\ Paulo Q. Tenreiro and Ruben H. Heleno
}

J. M. Costa, L. P. da Silva and R. H. Heleno (rheleno@uc.pt), Centre for Functional Ecology, Univ. of Coimbra, PO Box 3046, PT-3001-455 Coimbra, Portugal. -JMC, LPS, J. A. Ramos, S. Timoteo and P. M. Araújo, Marine and Environmental Research Centre (IMAR/CMA), Univ. of Coimbra, Coimbra, Portugal. ST also at: School of Biological Sciences, Univ. of Bristol, Bristol, UK. - M. S. Felgueiras, A Rocha - Associação Cristã de Estudo e Defesa do Ambiente, Mexilhoeira Grande, Portugal. - A. Rosa, Santarém, Portugal. - C. Matos, Coimbra, Portugal. - P. Encarnação, Inst. da Conservação da Natureza e das Florestas (ICNF), Estação Ornitológica Nacional, Santo André, Portugal. - P. Q. Tenreiro, Inst. da Conservação da Natureza e das Florestas (ICNF), Reserva Natural do Paul de Arzila, Mata Nacional do Choupal, PT-3000 Coimbra, Portugal.

\begin{abstract}
Fruits and seeds are critical food sources for many European passerines during the autumn migration, which in turn contribute to disperse seeds either internally, i.e. after ingestion (endozoochory), or externally, when seeds adhere to the body surface (epizoochory). Despite the recognized importance of birds as seed dispersers, the vast majority of studies focused on endozoochory while the external transport of seeds is frequently invoked as being potentially important, but remains largely unexplored. This is particularly important during the post-breeding migration of passerines, the most ubiquitous and diverse movement of potential seed carriers across Europe and into Africa, which coincides with the fruiting peak of many plant species (August-October). Our aim was to evaluate the role of migrating birds as potential long-distance seed dispersers, and comparing the prevalence of epizoochory and endozoochory during post-breeding migration. We sampled 926 wild birds in nine locations in Portugal, and retrieved 1833 seeds of 19 plant species dispersed internally and only three seeds externally attached to three birds (Serinus serinus, Locustella naevia and Turdus merula), showing an endozoochory prevalence 85 times higher than that of epizoochory. Migrating and non-migrating passerines dispersed seeds equally. While two of the seeds transported externally had specific adaptations to epizoochory, namely spines (Torilis arvensis) and hooks (Galium aparine), the third is a large seed from a fleshy-fruited plant, Frangula alnus (i.e. typical endozoochorous syndrome). These seeds were found on bird species with different diets, but similar behaviour (ground foragers) and in similar habitats (open agro-ecosystems). Our results highlight the strong role of migrating passerines as potentially longdistance seed dispersers and show that, at least in the autumn, the prevalence of epizoochory is several orders of magnitude lower than that of endozoochory.
\end{abstract}

Seed dispersal is an important process in the life cycle of most plants, influencing community composition and ecosystem stability (Nathan and Muller-Landau 2000). The advantages of seed dispersal can be resumed into three broad categories: 1) enabling seeds and seedlings to escape from high mortality near conspecifics due to predation, pathogens and competition (escape hypothesis), 2) allowing the colonization of favourable sites unpredictable in space and time (colonization hypothesis), and 3) promoting the non-random dispersal towards sites with particularly suitable conditions for survival (directed dispersal hypothesis) (Janzen 1971, Howe and Smallwood 1982, Wenny 2001). While plants can have short-distance dispersal mechanisms (autochory), they must rely on external vectors, such as water currents (hydrochory), wind (anemochory), and particularly animals (zoochory) for long distance dispersal (Ridley 1930). Specifically, animals can disperse seeds either internally, when viable seeds are defecated after (endozoochory) or externally, when seeds get attached to the animals fur or feathers (epizoochory) (Van der Pijl 1982). Diaspores, i.e. the plant structures that are actually transported, frequently have a series of morphological adaptations that promote their dispersal by a specific mechanism; these groups of traits are known as dispersal syndromes. For example, light seeds with wings or plumes can more easily be transported by wind, and fleshy nutritious tissues attract animals that will disperse their seeds after ingesting the fruits (Howe and Smallwood 1982).

Because some seeds can adhere to the body surface for large periods, these can potentially be dispersed over much longer distances by epizoochory than by endozoochory (Sorensen 1986, Whelan et al. 2008). However, while endozoochory in birds has been intensively studied all over the 
world (Forget et al. 2011), epizoochory has been largely neglected (Sorensen 1986). Diaspores adapted to epizoochory usually have barbs, hooks, spines or viscid mucilage, which enable the external adhesion to the body of animals (Fahn and Werker 1972, Sorensen 1986, Yang et al. 2012). The effectiveness of such adaptations will largely determine the retention time and the dispersal distance (Sorensen 1986, Guttal et al. 2011).

By virtue of their worldwide distribution, abundance, and high mobility, birds are important frugivores and disperse many seeds from a large variety of fleshy- and dry-fruited plants (Whelan et al. 2008, Heleno et al. 2013). Passerines (order Passeriformes) comprise more than half of the known extant bird species (Edwards and Harshman 2008), and are present in nearly all terrestrial habitats, being particularly well represented in agro-forestry habitats, where seed and fruit producing plants are also common (Siriwardena et al. 1998, Robinson et al. 2001). During post-breeding migration, many passerine species that breed in temperate areas are highly frugivorous and potential long-distance dispersers of seeds either after ingestion (Herrera 1995) or by adhesion to their feathers (Choi et al. 2010), for example transporting seeds between stopover sites.

Despite the undisputable attraction of birds for ecologists and the potential importance of passerines for epizoochory, there is a strong bias towards epizoochory studies in mammals when compared to birds (Heinken and Raudnitschka 2002, Couvreur et al. 2004, Manzano and Malo 2006, Picard and Baltzinger 2012), and epizoochory in passerines remains largely unexplored. When epizoochory was studied in birds, it was almost invariably centred in waterbirds (Vivian-Smith and Stiles 1994, Figuerola and Green 2002, Brochet et al. 2010, Raulings et al. 2011, Aoyama et al. 2012). Among these studies only one compared the prevalence of endozoochory and epizoochory (Brochet et al. 2010). Similarly, to our knowledge only one study evaluated the prevalence of epizoochory in several orders of birds, including passerines (Choi et al. 2010). This study revealed an overall low epizoochory prevalence $(0.08 \%)$ and no seeds at all were found adhered to passerines. Our aim was to evaluate the role of migrating birds as potential long-distance seed dispersers, comparing their internal and external seed loads during post-breeding migration, by comparison to those of resident birds.

\section{Material and methods}

We carried out a countrywide sampling to compare the prevalence of endozoochory and epizoochory by passerines in the post-breeding migratory period: during five consecutive days (10-14 September 2012) we simultaneously captured passerines (few individuals of other orders were also captured) in nine locations spread across $500 \mathrm{~km}$ from northern to southern Portugal (Fig. 1), in the Mediterranean basin global hotspot of biodiversity. We sampled in September because it corresponds to the peak of avian migration, and also to the peak of the fruiting period to most fleshy fruited plants. While the dry fruits of many annual plants, more likely dependent on epizoochory, are more abundant earlier in the year (early summer), these are still largely available in

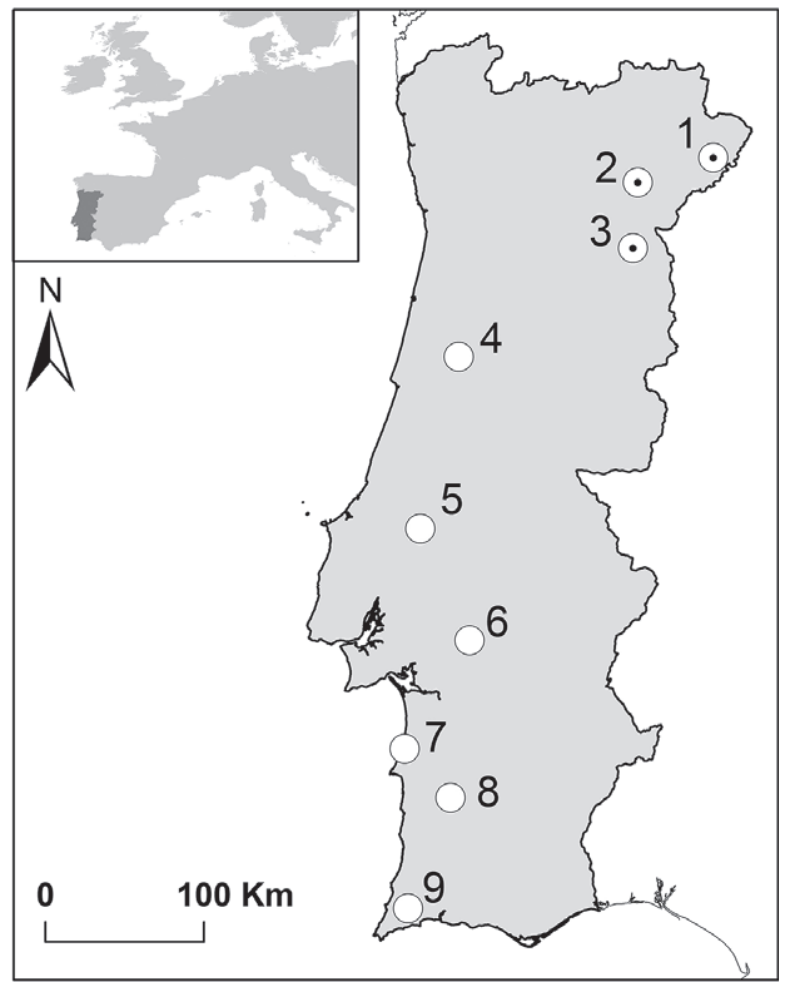

Figure 1. Geographic location of the study sites: 1) Atenor-Miranda do Douro, 2) Nozelos - Torre de Moncorvo, 3) Barragem de Santa Maria de Aguiar - Figueira de Castelo Rodrigo, 4) Larçã - Souselas, 5) Casais da Estrada - Achete, 6) Herdade do Freixo do Meio Foros de vale Figueira, 7) Lagoa de Santo André - Santiago do Cacém, 8) Água Branca - Odemira, and 9) Bensafrim - Lagos. Filled circles represent the three sites where epizoochory was detected.

September. We sampled simultaneously on all locations for five consecutive days to reduce temporal variation in the data, thus capturing a snapshot of seed dispersal by nonmigrating and migrating passerines at their stopovers. Our sampling locations were selected in a range of agro-forestry mosaic systems, the most common habitat type in Portugal. At each site, we operated mist nets during five hours after dawn (aprox. 06:30-11:30 a.m.), with visits at a maximum of 30 min intervals to extract mist-netted birds. During extraction, all birds were carefully inspected for external adhered seeds, before being placed in cotton bags for up to $30 \mathrm{~min}$ to defecate. After this period all produced droppings were collected, and birds were ringed, measured and released. A similar protocol and sampling effort was applied in all locations. Birds' droppings were air-dried and stored until processing. All intact seeds retrieved from droppings and feathers were later identified with a magnifying glass, by comparison with a reference collection of seeds in the Univ. of Coimbra. We considered each dropping containing at least one intact seed as one bird-plant interaction.

Each passerine species was classified as a migrant or resident at the time and location of sampling (Supplementary material Appendix 1), following Cabral et al. (2005). We considered migrant species those that are known longdistance migrants, i.e. those that can be found in Portugal only during part of the year (either for breeding, wintering or during migration towards lower or higher latitudes). Resident species are species from which most individuals remain 
in Portugal during the whole year. Finally, species with both migrant and resident populations were considered as partially-migratory.

The availability of seeds was estimated at each site by counting all ripe standing fruits and seeds along three linear transect of $25 \times 2 \mathrm{~m}$ running parallel to the mist nets.

Differences on the frequency of occurrence of endozoochorous and epizoochorous seeds on captured birds were assessed with a $\chi^{2}$-test. The correlation between the proportion of individuals across species dispersing seeds via endozoochory (frequency) and the number of plant species (diversity) was evaluated with a Spearman rank correlation test. In order to avoid artificially inflated percentages emerging from the bird species with very few captures, only species with more than 10 captures were included in the analysis. Differences between the number of plant species dispersed by migrating and resident birds was assessed with a MannWhitney test. Statistical significance was set at $p<0.05$. All statistical tests were implemented in $\mathrm{R}$ ver. 3.0.0.

Species interactions networks have recently emerged has a valuable tool to frame community wide process, such as seed dispersal, from a holistic viewpoint. We have applied a network approach to visualise all seed dispersal interactions, using specific code written in Mathematica ver. 9.0.

\section{Results}

We captured 926 birds from 54 species, 29 families and six orders (Passeriformes, 48 species; Coraciiformes, 2; Caprimulgiformes, Piciformes, Accipitriformes, Strigiformes,
1 each) (Supplementary material Appendix 1). As we were only interested in seed dispersal by passerines, and non-passerines did not disperse any seed (Supplementary material Appendix 1), we excluded these from further analysis. Overall 1833 seeds of 19 native plant species were retrieved from 254 droppings produced by 20 bird species; these interactions are represented in Fig. 2. All bird dispersing seeds were native passerines. All seeds were identified to species-level, with the exception of two species that were identified to family-level and morphotyped (Poaceae sp. 1 and sp. 2).

The vast majority of all retrieved seeds (98.8\%) were found in the droppings of captured birds and only three seeds $(1.2 \%)$ were found externally attached to the birds plumage, hence endozoochory was significantly more common $\left(\chi^{2}=161.1, \mathrm{DF}=1, \mathrm{p}<0.001\right)$.

Rubus ulmifolius was by far the most dispersed plant (53.3\% of all bird-plant interactions, dispersed by 17 species; Fig. 2). Indeed, this species was the most dispersed in all but one site (Vale Soeiro), where Rhamnus alaternus was the most dispersed species. Regarding the dispersers, the blackcap dispersed the most plants (10 species), followed by the garden warbler $S$. borin (nine species), the sardinian warbler $S$. melanocephala, and the robin (both with eight species). However, the garden warbler was the species that most frequently dispersed seeds $(71.7 \%$, 43 out of 60 individuals; excluding the western bonneli's warbler Phylloscopus bonelli with just one individual caught). There was a positive correlation between the frequency and the diversity of seeds in bird droppings $\left(n=13, r_{s}=0.71, p<0.006\right)$. Together, migrant and partially migrant birds seem to disperse plant species more

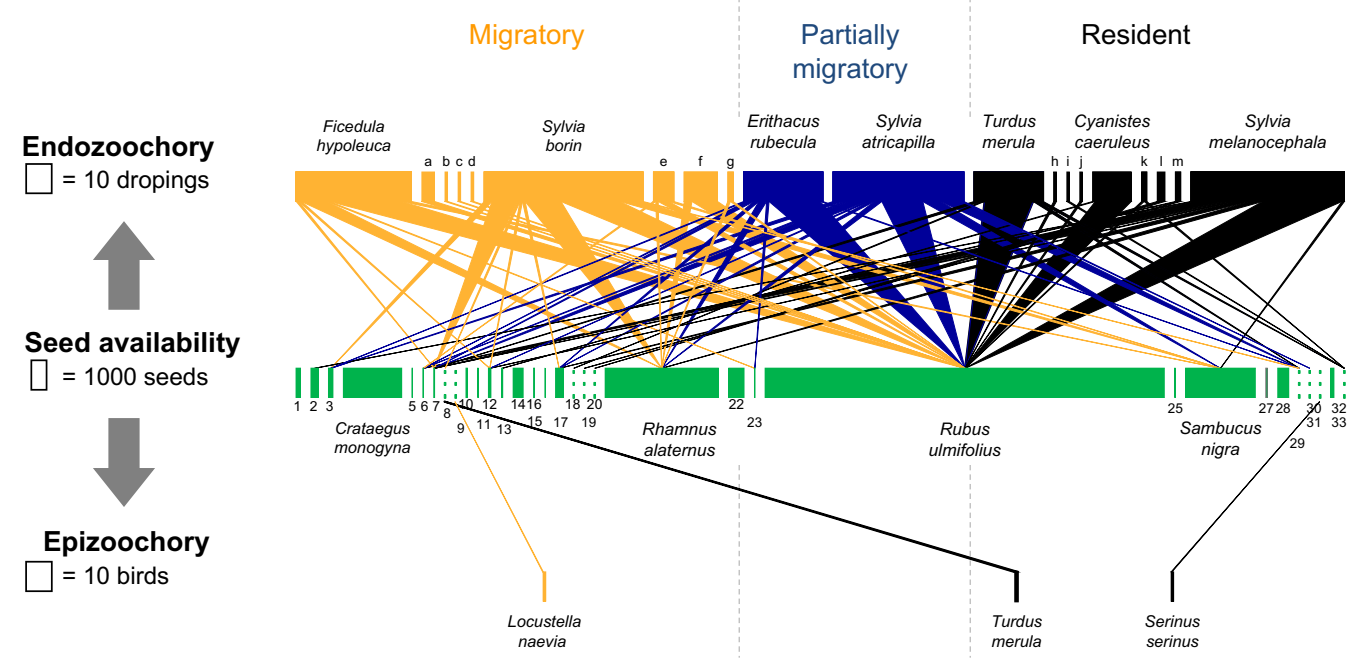

Figure 2. Representation of the dispersal of seeds (center) by birds via endozoochory (top level) and via epizoochory (bottom level). Species are represented by boxes. The width of the central boxes represent fruit availability (number of fruits and seeds counted along linear transects at each location), the width of the top and bottom box is proportional to the importance of each bird species as disperser (frequency of occurrence of intact seeds in bird droppings). Migrant birds are shown in yellow, partially migrant birds in blue, and resident birds in black. Dotted lines indicate dispersed seed species that were not detected in the fruit census. Birds: a - Luscinia megarhynchos, b - Muscicapa striata, c - Phylloscopus boneli, d - Phylloscopus trochilus, e - Sylvia cantillans, $\mathrm{f}$ - Sylvia communis, g - Phoenicurus phoenicurus, h - Emberiza cia, i - Sturnus unicolor, $\mathrm{j}$ - Cettia cetti, $\mathrm{k}$ - Cyanopica cyanus, 1 - Fringilla coelebs, $\mathrm{m}$ - Passer domesticus. Plants: 1 - Arbutus unedo, 2 - Asparagus acutifolius, 3 - Bryonia dioica, 5 - Cydonia oblonga, 6 - Daphne gnidium, 7 - Ficus carica, 8 - Frangula alnus, 9 - Galium aparine, 10 - Juncus effusus, 11 - Lonicera caprifolium, 12 - Lonicera implexa, 13 - Myrtus communis, 14 - Olea europaea, 15 - Osyris alba, 16 - Phillyrea angustifolia, 17 - Pistacia lentiscus, 18 - Poaceae sp. 1, 19 - Poaceae sp. 2, 20 - Portulaca oleracea, 22 - Rosa canina, 23 - Rubia peregrina, 25 - Ruscus aculeatus, 27 - Scirpoides holoschoenus, 28 - Smilax aspera, 29 - Solanum nigrum, 30 - Tamus communis, 31 - Torilis arvensis, 32 - Viburnum tinus, 33 - Vitis vinifera. 

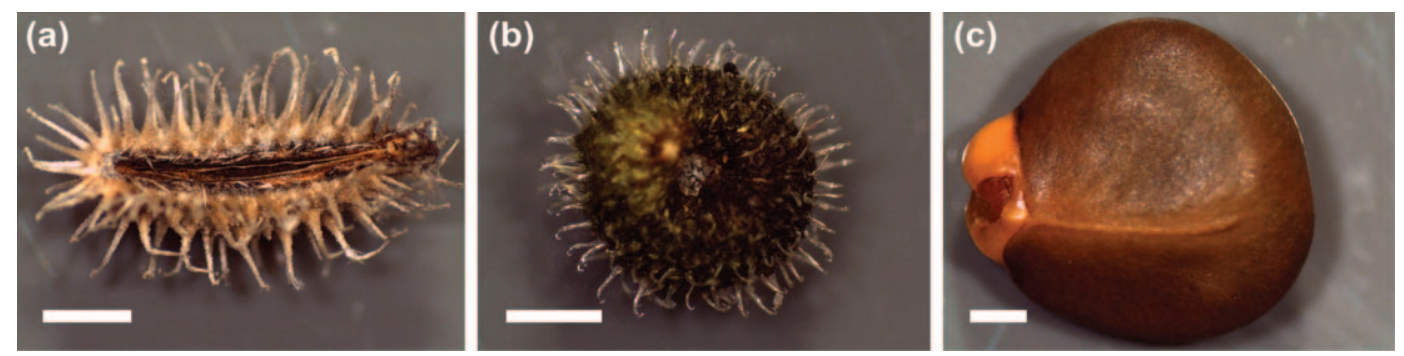

Figure 3. Picture of the three seeds recovered in this study, transported via epizhoochory by birds: (a) Torilis arvensis, (b) Galium aparine, and (c) Frangula alnus. Inset scale bars $=1 \mathrm{~mm}$.

often than resident birds (Fig. 2), but this difference was not statistically significant (Mann-Whitney test: $\mathrm{Z}=-1.758$, $\mathrm{n}=20$ migrators, $\mathrm{n}=28$ residents, $\mathrm{p}=0.079$ ).

Only three seeds were found externally adhered to bird feathers: one seed of Torilis arvensis on a serin Serinus serinus (granivorous - resident), one seed of Frangula alnus on a blackbird Turdus merula (frugivorous - resident), and one seed of Galium aparine on a grasshopper warbler Locustella naevia (insectivorous - migratory) (Fig. 2, 3). Such findings result on an overall epizoochory prevalence of $0.33 \%, 85$ times lower than that of endozoochory ( 3 and 254 interactions, respectively). These seeds were found on the side of the neck, nape, and belly of the hosts, respectively, and were recovered from the three northernmost locations (Table 1). The three seeds recovered are from native species and only the grasshopper warbler is an exclusive migrant disperser. These locations are essentially composed by a matrix of scrubland and low-intensity agricultural fields on rivers beds, with dispersed olive Olea europaea, almond Prunus amygdalus and holm oak Quercus rotundifolia trees and abundant herbaceous vegetation.

\section{Discussion}

In this study we found a much lower prevalence of epizoochory $(0.33 \%)$ than endozoochory $(27.8 \%)$ in passerines during post-breeding migration. Despite our care in searching for seeds attached to birds we cannot rule out the hypothesis that some adhered seeds have detached or that seeds were evacuated in faeces while the birds were on the net. Similarly it is possible that some larger seeds are quickly regurgitated and thus not found in the droppings, however the only species found during the seed availability transects that was most likely to be regurgitated due to its size $(>5 \mathrm{~mm})$ are the seeds of Olea europaea, which were still unripe in September and therefore are not relevant for migrating birds. Furthermore, any seed regurgitated inside the bird holding bags would have been collected and included in the analysis. Despite these eventual drawbacks, the total number of passerines that we caught and the large spatial replication make us confident that our results are representative of the phenomenon during the migratory period in this group of birds.

We found no significant differences in the prevalence of endozoochory between migratory and resident passerines. Most resident species are insectivorous or granivorous, seldom dispersing seeds, however, two resident species, the blackbird and the Sardinian warbler, are important dispersers (of five and eight plant species, respectively), which contributed to the lack of statistical difference. However, the biological importance of migrating passerines relatively to residents may be higher because the former have more species dispersing more plant species than the latter (Supplementary material Appendix 1). Most seeds were dispersed by migrating species, highlighting a strong potential for long-distance seed dispersal.

Even non-typically frugivorous birds, such as highly insectivorous, e.g. blue tit Cyanistes caeruleus and pied flycatcher Ficedula hypoleuca, and granivorous, e.g. house sparrow Passer domesticus and chaffinch Fringilla coelebs contributed to the dispersal of several species (Fig. 2). Insectivorous birds species feed on fruits as a nutritional complement (Fuentes 1994), while seed-predators may disperse seeds when these are not destroyed during ingestion and digestion (Heleno et al. 2011). The finding of 19 intact seeds of Portulaca oleracea, along with many remains of destroyed $P$. oleracea seeds in three chaffinch droppings renders further evidence

Table 1. Captured passerines and seeds dispersed per study site. Diversity represents the number of species, and abundance the total number of passerines captured or seeds dispersed.

\begin{tabular}{|c|c|c|c|c|c|c|}
\hline \multirow[b]{2}{*}{ Site } & \multicolumn{2}{|c|}{ Passeriformes } & \multicolumn{2}{|c|}{ Endozoochory } & \multicolumn{2}{|c|}{ Epizoochory } \\
\hline & Diversity & Abundance & Diversity & Abundance & Diversity & Abundance \\
\hline Bensafrim & 17 & 40 & 4 & 95 & 0 & 0 \\
\hline Odemira & 14 & 43 & 4 & 24 & 0 & 0 \\
\hline Santo André & 13 & 51 & 1 & 15 & 0 & 0 \\
\hline Freixo do Meio & 15 & 68 & 2 & 75 & 0 & 0 \\
\hline Achete & 26 & 155 & 10 & 434 & 0 & 0 \\
\hline Vale Soeiro & 13 & 82 & 6 & 138 & 0 & 0 \\
\hline Sta. Maria Aguiar & 26 & 225 & 7 & 563 & 1 & 1 \\
\hline Nozelos & 21 & 128 & 7 & 315 & 1 & 1 \\
\hline Atenor & 27 & 122 & 5 & 174 & 1 & 1 \\
\hline
\end{tabular}


for this process. Thus, our results support the idea of a continuum of frugivory translated in seed dispersal instead a dichotomized view between dispersers and non-dispersers, as described by Heleno et al. (2011).

The few studies that quantified epizoochory on birds, almost exclusively centred in waterbirds, found variable levels of seeds adhered on birds' feathers and feet. VivianSmith and Stiles (1994) found that 78\% of individuals of four waterbird species in the USA, transported seeds from 12 salt marsh plant species mostly attached to their feathers but also some on mud adhered to feet. In Spain, Figuerola and Green (2002) found that $35-100 \%$ of individuals from six waterbirds species carried propagules attached to their body; unfortunately no distinction was made between seeds and invertebrate propagules in this analysis. Regarding seeds alone, most were found adhered to the birds' feathers. More recently, Brochet et al. (2010) found diaspores (seeds and Chara sp. oogonia) attached on feathers and feet of $18 \%$ of inspected teals Anas crecca in France. These authors suggest a similar prevalence of endozoochory (20\%), but they did not consider only seeds, which hinders a comparison with our study. Also in waterfowls, it was estimated that $22 \%$ of individuals of pacific black duck $A$. superciliosa and chestnut teal A. castanea carried at least one viable seed (Raulings et al. 2011). In the Ogasawara Islands, Japan, Aoyama et al. (2012) found epizoochory rates ranging from 16-32\% for four species of seabirds. To our knowledge, only one study evaluated the prevalence of epizoochory on a diverse assemblage of birds, which included passerines (Choi et al. 2010), reporting, like in our study, a very low prevalence of epizoochory $(0.08 \%)$ and no seeds at all found in passerine species.

The seeds of $T$. arvensis and $G$. aparine were attached to the birds' feathers by their specific adaptations to epizoochory: spines and hooks, respectively (Fig. 3). However, the epizoochory of the fleshy-fruited $F$. alnus is more puzzling as these seeds are considerably larger (ca 5-6 mm), without ornamentation and are generally ingested along with the fleshy pulp and dispersed by endozoochory (Hampe 2001). Naturally, the presence of a certain dispersal syndrome does not prevent the dispersal of seeds by other (non-standard) mechanism (Higgins et al. 2003, Thomson et al. 2010). The transport of seeds without anchoring structures via epizoochory has been previously reported (Figuerola and Green 2002, Brochet et al. 2010, Raulings et al. 2011, Aoyama et al. 2012). However, in most cases such seeds either have structures that promote anemochory, which allow some anchoring to feathers, or they are very small seeds that can easily be arrested in mud on bird's feet (Carlquist 1966). Neither of these situations applies to $F$ alnus seeds. We hypothesise that residues of the fruits fleshy-pulp promoted the adhesion of the seed to the blackbird's nape presumably when the bird was foraging. A similar situation may occur when seeds remain glued to feathers after defecation. Although most blackbirds and serins are resident in Portugal, the grasshopper warbler is a passing migrant which might be highly relevant given the disproportional importance of long-distance dispersal events for plant population dynamics (Nathan 2006). Epizoochorous seeds anchored to a migrating bird can potentially be dispersed over thousands of $\mathrm{km}$ (until the bird dies or the seed gets detached). This long-distance dispersal allows plant species to eventually colonize new areas, and can be especially troublesome in case of invasive species (Choi et al. 2010).

Our results offer support to the empirical suggestion in Nogales et al. (2012) that epizoochory in terrestrial birds must be 'extremely' rare. Despite the differences in sample size, our estimated prevalence of epizoochory was similar to that of Choi et al. (2010): 0.33 and $0.08 \%$, respectively. However, we estimate a much lower frequency of epizoochory in terrestrial birds than that commonly found in waterbirds. Epyzoochory results from the passive contact between the seeds and the animals (Burger 2005). Therefore it seems likely that epizoochory will be more frequent in birds that forage or nest on the ground, and particularly in habitats where epizoochorous plants (such as many annual grasses) or plants with small seeds are abundant. Furthermore, humid conditions, such as those in marshes, are likely to increase the frequency of epizoochory by promoting the adhesion of small seeds to mud on animals' feet, regardless of adhesive structures of the seeds. In effect, the three passerine species carrying seeds on their plumage are species that usually live in habitats rich in herbaceous plants, and that tend to feed on the ground (Fernández-Juricic 2001, Cramp and Simmons 2004), despite having different diets (blackbird - frugivore, serin - granivore, grasshopper warbler - insectivore). Finally, all other things being equal, larger body sized birds are more likely to disperse seeds externally given their larger surface area. Thus, habitat, behaviour, and body size may explain the dissimilarity in epizoochory figures between reported for waterbirds and those presented here for passerines. Accordingly, all birds reported as carrying seeds externally in previous studies have in common the fact that they live in habitats rich in plants that produce seeds prone to adhere to birds' body, and feed or nest on the ground (Vivian-Smith and Stiles 1994, Figuerola and Green 2002, Brochet et al. 2010, Choi et al. 2010, Raulings et al. 2011, Aoyama et al. 2012).

\section{Concluding remarks}

In our study, the prevalence of endozoochory was 85 times higher than that of epizoochory in post-breeding migrating passerines in Portugal. Given that plants with epizoochorous seeds might be more abundant in other times of the year, further sampling is needed in order to allow more general quantification of this phenomenon in passerines. Given the high number of ecological studies focused on birds and the almost five million birds captured and marked annually in Europe alone (EURING 2007), such more precise estimates seem to be a very realistic prospect in the near future.

Acknowledgements - We thank the Portuguese ringing scheme (CEMPA/ICNF) for providing bird rings and specific permits, Jane Memmott for sharing network drawing code, and the team of the Centre for Functional Ecology and the Coimbra Botanical Garden, particularly to Arménio Matos for his help on seed identifications. We also thank to Javier Pérez-Tris for valuable comments. 


\section{References}

Aoyama, Y., Kawakami, K. and Chiba, S. 2012. Seabirds as adhesive seed dispersers of alien and native plants in the oceanic Ogasawara Islands, Japan. - Biodivers. Conserv. 21: 2787-2801.

Brochet, A. L., Guillemain, M., Fritz, H., Gauthier-Clerc, M. and Green, A. J. 2010. Plant dispersal by teal (Anas crecca) in the Camargue: duck guts are more important than their feet. - Freshwater Biol. 55: 1262-1273.

Burger, A. E. 2005. Dispersal and germination of seeds of Pisonia grandis, an Indo-Pacific tropical tree associated with insular seabird colonies. - J. Trop. Ecol. 21: 263-271.

Cabral, M. J., Almeida, J., Almeida, P. R., Delliger, T., Ferrand de Almeida, N., Oliveira, M. E., Palmeirim, J. M., Queirós, A. I., Rogado, L., Santos-Reis, M. 2005. Livro vermelho dos vertebrados de Portugal. - Inst. de Conservação da Natureza, Lisboa.

Carlquist, S. 1966. The biota of long-distance dispersal. I. Principles of dispersal and evolution. - Q. Rev. Biol. 41: 247-270.

Choi, C. Y., Nam, H. Y. and Chae, H. Y. 2010. Exotic seeds on the feathers of migratory birds on a stopover island in Korea. - J. Ecol. Field Biol. 33: 19-22.

Couvreur, M., Christiaen, B., Verheyen, K. and Hermy, M. 2004. Large herbivores as mobile links between isolated nature reserves through adhesive seed dispersal. - Appl. Veg. Sci. 7: 229-236.

Cramp, S. and Simmons, K. 2004. BWPi: Birds of the Western Palearctic interactive (DVD-ROM). - BirdGuides, Sheffield, UK.

Edwards, S. V. and Harshman, J. 2008. Passeriformes. Perching birds, passerine birds. Ver. 24 June 2008 (under construction). - <http://tolweb.org/Passeriformes > accessed 19-01-2013.

EURING 2007. Bird ringing for science and conservation bird ringers and ringing centers. $-<$ www.euring.org/about euring/brochure2007/06ringers_and_centres.htm $>$ accessed 14-01-2013.

Fahn, A. and Werker, E. 1972. Anatomical mechanisms of seed dispersal. - In: Koslowky, T. (ed.), Seed biology. Academic Press, pp. 151-221.

Fernández-Juricic, E. 2001. Avian spatial segregation at edges and interiors of urban parks in Madrid, Spain. - Biodivers. Conserv. 10: 1303-1316.

Figuerola, J. and Green, A. J. 2002. How frequent is external transport of seeds and invertebrate eggs by waterbirds? A study in Doñana, SW Spain. - Arch. Hydrobiol. 155: 557-565.

Forget, P.-M., Jordano, P., Lambert, J. E., Böhning-Gaese, K., Traveset, A. and Wright, S. J. 2011. Frugivores and seed dispersal (1985-2010); the 'seeds' dispersed, established and matured. - Acta Oecol. 37: 517-520.

Fuentes, M. 1994. Diets of fruit-eating birds: what are the causes of interspecific differences? - Oecologia 97: 134-142.

Guttal, V., Bartumeus, F., Hartvigsen, G. and Nevai, A. L. 2011. Retention time variability as a mechanism for animal mediated long-distance dispersal. - PLoS One 6: e28447.

Hampe, A. 2001. The role of fruit diet within a temperate breeding bird community in southern Spain. - Bird Study 48: 116-123.

Heinken, T. and Raudnitschka, D. 2002. Do wild ungulates contribute to the dispersal of vascular plants in central European forests by epizoochory? A case study in NE Germany. - Forstwiss. Centralbl. 121: 179-194.

Supplementary material (Appendix JAV-00271 at <www. oikosoffice.lu.se/appendix $>$ ). Appendix 1.
Heleno, R. H., Ross, G., Everard, A., Memmott, J. and Ramos, J. A. 2011. The role of avian 'seed predators' as seed dispersers. - Ibis 153: 199-203.

Heleno, R. H., Ramos, J. A. and Memmott, J. 2013. Integration of exotic seeds into an Azorean seed dispersal network. - Biol. Invasions 15: 1143-1154.

Herrera, C. M. 1995. Plant-vertebrate seed dispersal systems in the Mediterranean: ecological, evolutionary and historical determinants. - Annu. Rev. Ecol. Syst. 26: 705-727.

Higgins, S. I., Nathan, R. and Cain, M. L. 2003. Are long-distance dispersal events in plants usually caused by nonstandards means of dispersal? - Ecology 84: 1945-1956.

Howe, H. F. and Smallwood, J. 1982. Ecology of seed dispersal. - Annu. Rev. Ecol. Syst. 13: 201-228.

Janzen, D. H. 1971. Seed predation by animals. - Annu. Rev. Ecol. Syst. 2: 465-492.

Manzano, P. and Malo, J. E. 2006. Extreme long-distance seed dispersal via sheep. - Front. Ecol. Environ. 4: 244-248.

Nathan, R. 2006. Long-distance dispersal of plants. - Science 313: 786-788.

Nathan, R. and Muller-Landav, H. C. 2000. Spatial patterns of seed dispersal, their determinants and consequences for recruitment. - Trends Ecol. Evol. 15: 278-285.

Nogales, M., Heleno, R., Traveset, A. and Vargas, P. 2012. Evidence for overlooked mechanisms of long-distance seed dispersal to and between oceanic islands. - New Phytol. 194: 313-317.

Picard, M. and Baltzinger, C. 2012. Hitch-hiking in the wild: should seeds rely on ungulates? - Plant Ecol. Evol. 145: 24-30.

Raulings, E., Morris, K., Thompson, R. and Nally, R. M. 2011. Do birds of a feather disperse plants together? - Freshwater Biol. 56: 1390-1402.

Ridley, H. N. 1930. The dispersal of plants throughout the world. - Reeve and Co., Ashford.

Robinson, R. A., Wilson, J. D. and Crick, H. Q. P. 2001. The importance of arable habitat for farmland birds in grassland landscapes. - J. Appl. Ecol. 38: 1059-1069.

Siriwardena, G. M., Baillie, S. R., Buckland, S. T., Fewster, R. M., Marchant, J. H. and Wilson, J. D. 1998. Trends in the abundance of farmland birds: a quantitative comparison of smoothed Common Birds Census indices. - J. Appl. Ecol. 35: $24-43$.

Sorensen, A. E. 1986. Seed dispersal by adhesion. - Annu. Rev. Ecol. Syst. 17: 443-463.

Thomson, F. J., Moles, A. T., Auld, T. D., Ramp, D., Ren, S. and Kingsford, R. T. 2010 Chasing the unknown: predicting seed dispersal mechanisms from plant traits. - J. Ecol. 98: $1310-1318$

Van der Pijl, L. 1982. Principles of dispersal in higher plants. - Springer.

Vivian-Smith, G. and Stiles, E. W. 1994. Dispersal of salt marsh seeds on the feet and feathers of waterfowl. - Wetlands 14: 316-319.

Wenny, D. G. 2001. Advantages of seed dispersal: a re-evaluation of directed dispersal. - Evol. Ecol. Res. 3: 51-74.

Whelan, C. J., Wenny, D. G. and Marquis, R. J. 2008. Ecosystem services provided by birds. - Ann. N. Y. Acad. Sci. 1134: $25-60$.

Yang, X., Baskin, J. M., Baskin, C. C. and Huang, Z. 2012. More than just a coating: ecological importance, taxonomic occurrence and phylogenetic relationships of seed coat mucilage. - Perspect Plant. Ecol. Evol. Syst. 14: 434-442. 